\section{BM Paediatrics Open}

\title{
Breastfeeding disruption during hospitalisation for bronchiolitis in children: a telephone survey
}

Claire Heilbronner, ${ }^{1}$ Emeline Roy, ${ }^{2}$ Alice Hadchouel, ${ }^{3}$ Sabrine Jebali, ${ }^{4}$ Siwar Smii, ${ }^{4}$ Alexandra Masson, ${ }^{1}$ Sylvain Renolleau, ${ }^{1}$ Virginie Rigourd ${ }^{4}$

To cite: Heilbronner C, Roy E, Hadchouel A, et al. Breastfeeding disruption during hospitalisation for bronchiolitis in children: a telephone survey. BMJ Paediatrics Open 2017;1:e000158. doi:10.1136/ bmjpo-2017-000158

- Additional material is published online only. To view please visit the journal online (http://dx.doi.org/10.1136/ bmjpo-2017-000158).

Received 13 June 2017 Revised 7 September 2017 Accepted 10 September 2017

\section{(a) CrossMark}

${ }^{1}$ Pediatric Intensive Care Unit, Assistance Publique-Hopitaux de Paris, Necker Hospital-Sick Children, Paris, France 2Pediatric Department, Assistance Publique-Hopitaux de Paris, Necker Hospital-Sick Children, Paris, France ${ }^{3}$ Department of Pediatric Pulmonology, Assistance Publique-Hopitaux de Paris, Necker Hospital-Sick Children, Paris, France

${ }^{4}$ Region lle de France Human Milk Bank, Assistance PubliqueHopitaux de Paris, Necker Hospital-Sick Children, Paris, France

Correspondence to Dr Claire Heilbronner; claire. heilbronner@aphp.fr

\section{ABSTRACT}

Background Hospitalisation for an acute bronchiolitis might lead to unwanted weaning off breast feeding for several reasons (respiratory distress, use of enteral or parenteral feeding, mothers tiredness, among others), yet it has never been really evaluated or quantified.

Methods We conducted this telephone survey to evaluate breastfeeding disruption during hospitalisation for bronchiolitis and try to identify its determining factors for future interventions. This cross-sectional study extends over one epidemic season of bronchiolitis in a tertiary care hospital. All patients aged 6 months or younger hospitalised with acute bronchiolitis and receiving at least partial breast feeding were eligible for the study $(n=144)$. Patients discharged home whose parents accepted to be contacted for a phone survey were included. Parents were contacted 3 months (range 0.5-6) after discharge.

Results Eighty-four patients were included in the study. Median length of hospital stay was 3 days $(1 ; 34)$, and 27 patients spent some time in paediatric intensive care unit. Forty-three mothers stated that hospitalisation modified their breast feeding (17 stopped, 12 switched to partial breast feeding and 14 reduced without stopping). Mothers stated that the causes of breastfeeding disturbance were lack of support and advices $(n=27)$ followed by child's respiratory disease $(n=14)$, logistic hospital difficulties $(n=13)$ and personal organisation issues $(n=4)$.

Conclusion Admission to hospital with bronchiolitis may adversely affect breast feeding. Correct advices and support could be a determining factor, and further studies should focus on preventive interventions.

\section{INTRODUCTION}

Breast feeding is a well-documented protective factor against respiratory diseases in children. ${ }^{1-3}$ Exclusive breast feeding should therefore be promoted, and international guidelines recommend to maintain it at least until the age of 6 months. ${ }^{12}$

Breast feeding though is not always easy. ${ }^{3} \mathrm{~A}$ recent survey estimated that $75 \%$ of infants were breast fed in maternity wards in France (including partial breast feeding), but only $40 \%$ of children were still partially breast fed after 3 months. ${ }^{45}$

\section{What is already known on this topic?}

Breast feeding may be affected during hospitalisation for bronchiolitis.

This issue has not been quantified and no data can support any intervention.

\section{What this study hopes to add?}

There is a high rate of breastfeeding disruption during hospitalisation for bronchiolitis.

- Lack of support for breast feeding was a major problem.

Children's health might influence breastfeeding continuation (quality of sucking, short breathing in respiratory or cardiologic diseases, mother/child separation, mother's fatigue, formula introduction).

In France, about 500000 infants are affected with acute bronchiolitis each year. ${ }^{6}$ Among children consulting at the emergency room, about $50 \%$ of children under 6 months (and 62\% under 3 months) require hospitalisation $^{7}$ and $10 \%-15 \%$ spend some time in paediatric intensive care unit (PICU) for respiratory support. ${ }^{8}$

Hospitalisation for an acute bronchiolitis might lead to unwanted weaning off breast feeding for several reasons:

- Dyspnea, sucking difficulties or even swallowing difficulties can occur.

- Enteral or parenteral feeding can be necessary, sometimes with formula milk.

- Mothers might not always be able to stay continuously with their child in hospital (either because of hospital accommodation or because of family situation, working issues, among others).

- Mothers might get stressed and tired, sleep badly, eat or drink less than usual or irregularly. 
- Breast milk expression might not always be easy in hospital by lack of material or caregiving attention.

- Caregivers might have different attitudes towards breast feeding and may give contradictory advices.

Only Lapillonne et al mention breastfeeding disturbance among the potential impacts of a hospitalisation for bronchiolitis..$^{9}{ }^{10}$ No study has been published to specifically measure breastfeeding disruption during hospitalisation for bronchiolitis, although the high number of patients affected makes it a potentially important health issue.

With no study available, no intervention can be proposed in national or international guidelines on bronchiolitis.

We conducted this preliminary study to try to measure the chance of breast feeding being impaired during a hospitalisation for bronchiolitis in children previously breast fed and to try to identify children, mother or hospital factors that might be associated with poor breastfeeding outcome for future intervention.

Our hospital participates in many actions to promote breast feeding, but it has not the 'Baby Friendly Initiative' accreditation.

\section{MATERIAL AND METHODS}

This study is a single-centre telephone survey conducted from 1 October 2015 to 15 February 152016 at Necker-Enfants Malades Hospital in Paris (tertiary care) in all wards attending to patients with acute bronchiolitis (paediatric ward, paediatric pulmonology ward and PICU).

Bronchiolitis was defined on the basis of history and physical examination as rhinorrhoea, cough, tachypnoea, wheezing, increased respiratory effort expressed by grunting, nasal flaring and intercostal and/or subcostal retractions. ${ }^{11}$ Apnoeic bronchiolitis in neonates was also included. Hospital admission was decided by emergency ward's attending physicians. PICU admission was decided according to intensivist's assessment. Standard care was given accordingly to both French and US latest guidelines. ${ }^{6}{ }^{11}$

\section{Study design}

Criteria for eligibility for the study:

- all infants under 6 months on admission

- with acute bronchiolitis and no other serious condition

- breast fed (at least partially) on admission

- discharged home.

All parents signed a consent form on admission allowing extraction of data from medical charts. Parents were also informed about this study during hospitalisation if possible (preinclusion) or received information either by mail or by email when reached on the phone for the survey itself.

We included all patients whose parents spoke French, had been informed about the study and accepted to answer a standardised survey on the phone after discharge. Parents were contacted 3 months (range $0.5-6)$ after discharge.
We did not include parents that could not be reached on their phone. Patients could not be included twice in the event of recurrent bronchiolitis during the study period.

We made the hypothesis that bronchiolitis would be associated with alterations of breast feeding and that severity of bronchiolitis would be associated with unwanted weaning. We also aimed at identifying patients or hospital conditions at risk of breastfeeding disruption and that might be targeted in future interventions.

Data collection included:

- data collected from the caregivers (both paramedical and medical staff): patient-to-nurse ratio, existence of breastfeeding experts among caregivers;

- data extracted from the charts: growth evaluation (birth weight, growth, weight on admission and at discharge), length of stay, PICU requirements, length of oxygen or ventilatory support requirement, enteral or parenteral nutritional support, room accommodation during hospitalisation;

- answers from the survey (see online supplementary file 1) concerning past and present occupation and family situation (basic social background) that could be relevant to explain weaning off breast feeding, tobacco exposure, breastfeeding help and material (breast pump, freezer) available during hospital stay;

- answers from the survey (see online supplementary file 1) concerning total or partial weaning off breast feeding at discharge or in the fortnight following discharge, mother's opinion on the cause of the weaning (severity of the bronchiolitis, lack of support, personal organisation issues and/or logistic issues in hospital ward), mother's opinion and satisfaction about breastfeeding support during hospitalisation.

When the mothers did not have sufficient time to answer all the questions on the phone, the questions about occupation, familial situation and tobacco exposure were skipped from the survey.

The study was approved by the ethical board of the French Pediatric Society (CER_SFP 2015_009_2).

\section{Statistical analysis}

Data are expressed as median values (with minimum and maximum values) for continuous variables and number for binary or categorical data.

Student's t-test was used for qualitative (categorical) variables. For comparison of non-parametric means, Wilcoxon's test was used if necessary for quantitative (numerical) criteria, while $\chi^{2}$ and Fisher's exact tests were used to compare qualitative criteria. $p$ Values $<0.05$ were considered statistically significant.

Analyses were performed with Biostat TGV software.

\section{RESULTS}

During the study period, 332 patients under 6 months were hospitalised at our hospital for 345 episodes of bronchiolitis (figure 1). Among these, 144 patients were breast fed, totally $(\mathrm{n}=107)$ or partially $(\mathrm{n}=37)$. Four were 


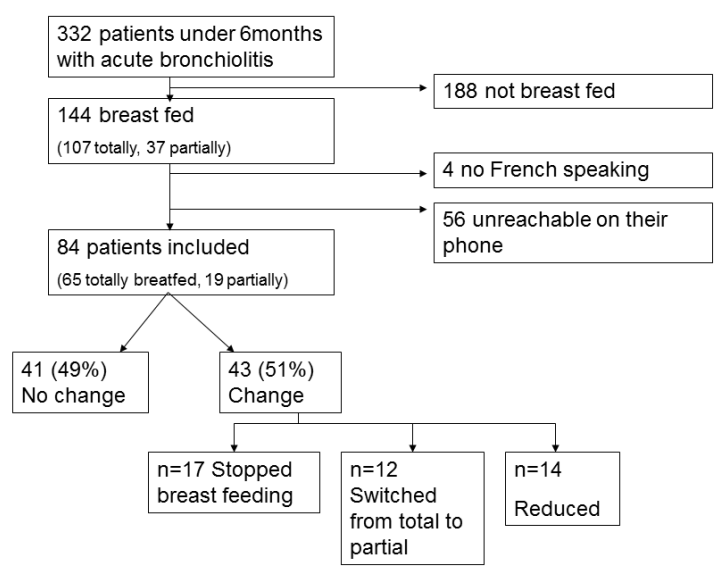

Figure 1 Flow diagram.

not included because they did not speak any French, and 56 did not answer their phone despite several calls at different times of the day; 84 patients could be included in the study. The median delay for phone contact was 3 months $(0.5 ; 6)$.

Among eligible patients, no significant difference could be observed regarding length of stay, need for PICU, respiratory support and nutritional support between included $(\mathrm{n}=84)$ and non-included patients $(\mathrm{n}=60)$.

\section{Bronchiolitis description $(\mathrm{n}=84)$}

Median length of stay for all breastfed patients was 3 days $(1 ; 34) ; 27$ patients spent some time in PICU (median length in PICU: 3 days $(1 ; 26)$ ). One patient needed invasive ventilation for 10 days, 18 received either non-invasive ventilation or high-flow oxygen for 3 days $(1 ; 9), 34$ patients received standard oxygen for 3 days $(1 ; 7)$ and 34 patients received no respiratory support during hospitalisation. No patient died of bronchiolitis during the study period. Regarding feeding difficulties, 45 patients received nutritional support, either by enteral feeding $(n=38)$ or parenteral nutrition $(n=5)$ or both $(n=2)$.

\section{Socioeconomic background $(n=54)$}

Answers about socioeconomic background were available for 54/84 patients. Most breastfeeding mothers $(n=52)$ did not smoke and lived as a couple $(\mathrm{n}=53)$. Concerning occupation, 1 mother was working at the time of hospitalisation, 28 were on maternity leave, 10 were on a parental education leave and 15 were housewives.

\section{Breast feeding during hospitalisation $(n=84)$}

Sixty-five patients were exclusively breast fed before; the others received both breast milk and formula milk. Forty-three mothers stated that their breast feeding had been modified by the hospitalisation of their child, either moderately $(n=19)$ or totally $(n=17)$.

Among those 43 mothers:

- 17 stopped breast feeding
Table 1 Baseline and evolution comparison between groups

\begin{tabular}{|c|c|c|}
\hline & $\begin{array}{l}\text { Modified } \\
\text { breast feeding } \\
(n=43)\end{array}$ & $\begin{array}{l}\text { Non-modified } \\
\text { breast feeding } \\
(n=41)\end{array}$ \\
\hline Birth weight $(g)^{*}$ & $\begin{array}{l}3330(1010 \\
4160)\end{array}$ & $\begin{array}{l}3180(1050 \\
4695)\end{array}$ \\
\hline Gestational age $(\mathrm{GW})^{*}$ & $38(26 ; 39)$ & $37(25 ; 40)$ \\
\hline $\begin{array}{l}\text { Mean growth before } \\
\text { hospitalisation }(g / d)^{\star}\end{array}$ & $26(-10 ; 112)$ & $30(0 ; 213)$ \\
\hline $\begin{array}{l}\text { Exclusive breast feeding } \\
\text { beforehospitalisation }^{\star \star}\end{array}$ & 35 & 30 \\
\hline Age on admission $(\mathrm{d})^{\star}$ & $34(3 ; 166)$ & $50(16 ; 159)$ \\
\hline Length of stay $(d)^{\star}$ & $3(1 ; 34)$ & $3(1 ; 14)$ \\
\hline Length of PICU $(d)^{*}$ & $3(1 ; 26)$ & $4(1 ; 14)$ \\
\hline Length of ventilation $(d)^{\star}$ & $3(1 ; 9)$ & $3(1 ; 6)$ \\
\hline $\begin{array}{l}\text { Length of oxygen } \\
\text { requirement }(d)^{\star}\end{array}$ & $3(1 ; 7)$ & $3(1 ; 5)$ \\
\hline $\begin{array}{l}\text { Enteral or parenteral } \\
\text { nutrition }^{\star \star}\end{array}$ & 25 & 19 \\
\hline $\begin{array}{l}\text { Length of nutritional } \\
\text { support }(d)^{*}\end{array}$ & $2(1 ; 6)$ & $2(1 ; 13)$ \\
\hline
\end{tabular}

*Median (minimum, maximum).

${ }^{* *}$ number of patients.

d, day; GW, gestational weeks; PICU, paediatric intensive care unit.

- 12 switched from total breast feeding to partial breast feeding

- 14 reduced breast feeding without stopping or switching.

Remaining mothers $(41 / 84)$ stated that they kept breast feeding as before or that their breastfeeding modification was not due to hospitalisation but was a personal choice or a planned weaning.

Daily growth rate before hospitalisation and type of breast feeding before hospitalisation (as described in table 1) did not significantly differ between mothers who reduced or stopped breast feeding and those who continued to breastfeed normally.

The patients whose breast feeding was affected had a tendency to be younger $(\mathrm{p}=0.06)$.

No statistically significant difference was observed regarding medical severity of the bronchiolitis evaluated by length of stay, oxygen requirement or need for respiratory support, enteral or parenteral feeding during hospitalisation, growth evaluation on admission and PICU admission (table 1).

When asked about the causes of their breastfeeding difficulties, mothers who reduced breast feeding mentioned:

- $\mathrm{n}=27$ : lack of support and advices

- $\mathrm{n}=14$ : severity of child's respiratory disease

- $\mathrm{n}=13$ : logistics issues (difficulties to draw breast milk, availability of breast pumps, room accommodation and bedding for mothers, introduction of formula milk or baby bottle) 
- $\mathrm{n}=4$ : personal and family organisation issues due to hospitalisation (sitting the siblings, long journey home).

All children were in single rooms, and all mothers could sleep in the same room as their child.

Patient-to-nurse ratio was $3: 1$ in ICU and $6: 1$ or 7:1 in paediatric ward and pulmonology ward. Each ward had several breastfeeding experts among doctors or nurses.

Data about prior experience with breast feeding were available for 63 breastfeeding mothers. Mothers in the study had a median number of children of $2(1 ; 5)$ and had an experience of cumulated breast feeding for their children of 8 months $(0.9 ; 36)$. No difference was observed between groups regarding cumulated length of previous breast feeding for the elder children.

\section{DISCUSSION}

Our study showed a high rate of breast feeding on admission compared with epidemiological surveys ${ }^{45}$ and also a very high rate of breastfeeding disturbance during hospitalisation for bronchiolitis as previously suggested in a large multicentre study. ${ }^{910}$ Hospitalisation of infants for bronchiolitis in our survey lead to undesired weaning off breast feeding, transition to mixed breast feeding or even partial changes that may affect the nutritional balance suitable for infants and alter their protection against further respiratory events. ${ }^{12} 13$

Our study is subject to possible biases, the most important is that it is single centred.

Several local particularities could have influenced the results in our hospital:

- Increasing the number of nurses might help to better support breastfeeding mothers since it is a time-consuming activity, probably even more in an epidemic period with high workload. The nurse-to-patient ratio seemed correct in our wards, but we could not find much data about optimal ratio in the literature.

- It is possible that breastfeeding knowledge or involvement is not optimal among our caregivers despite the fact that all the nurses in our hospital are specifically trained for paediatrics. Hence, the results in our study give baseline information about what happens to breast feeding during bronchiolitis with no or minimal support from caregivers.

- Room accommodation could be considered non-optimal in our hospital, but we believe that it would be similar or possibly even worse in some other settings since our hospital is a referring and teaching hospital with most paediatric wards hosted in a new building inaugurated in 2013 and with all patients being bedded in single rooms with possible sleeping accommodation for parents.

The long time period between hospitalisation and survey is another possible bias for it could have altered the quality of answers from the mothers, but Lapillonne et al concluded in their study that interrogation as far as 6 months after hospitalisation can be considered as relevant to evaluate burden of hospitalisation. ${ }^{9}$ Moreover, this delay has helped not to include transitory modifications after hospitalisation and to only collect data on persistent alterations of breast feeding.

The last potential bias is that a significant amount of patients could not be reached on the phone. If we consider that all eligible mothers that we could not include in this survey continued their breast feeding with no disturbance (which is unlikely), we still have 43/144 mothers whose breast feeding was either stopped or altered.

Exclusive breast feeding was not a protective factor in our study, and we even noticed a non-significant tendency to the opposite (and a tendency for children with altered breast feeding to be younger). It is possible that very young infants about 10-15 days old are more frequently exclusively breastfed but are also those whose breast feeding is the more fragile. We should probably be more supportive for the mothers of those very young infants.

We expected to find severity of respiratory disease as the first factor for breastfeeding discontinuation, but only $32 \%$ of mothers pointed out the severity of disease as one of the causes for unwanted weaning. It is possible that the delay between discharge and phone call could have altered mother's perception, or that some guilty feelings about weaning off breast feeding might have influenced the answers, but objective evaluation of respiratory distress on medical charts (length of stay, PICU requirements, respiratory and nutritional support) did not differ between groups. It is possible that most severe patients with long PICU stay and invasive ventilation should be more impacted, but our study was not powerful enough to evaluate this. It is important to notice that breastfeeding disturbance observed in our patients occurred despite a short length of stay (median 3 days) and despite a good outcome of this acute but rather benign respiratory disease. Caregivers might be underestimating the possible impact of such a short stay on breast feeding and think that it will go back to normal after discharge, but this is not what we observed in our patients.

Lack of support from caregivers was the first factor pointed out by mothers after discharge. It is possible that this lack of support might be less important in other hospitals, especially in countries where breast feeding is better supported. Yet, although relying mostly on mothers' recall and perception, this information is still very important as it is modifiable for further practice. If other studies confirm the results of our survey, it could lead to recommendations of therapeutic interventions to prevent unwanted weaning during bronchiolitis, especially in younger infants for which breast feeding is still precarious.

Our data encourage us to endorse preventive measures in all wards hosting patients with bronchiolitis (even if children stay in hospital for a very short length of time) especially to support mothers during hospitalisation. 
We only studied bronchiolitis in hospital, but it is possible that children who do not require hospitalisation might also suffer from altered breast feeding; this should be evaluated in another prospective study involving outpatient's caregivers.

\section{CONCLUSION}

With no intervention, bronchiolitis in a breastfed infant is a hazardous situation for breast feeding with about half of mothers of hospitalised children either stopping or diminishing their breast feeding during hospitalisation.

These results should encourage caregivers to evaluate breast feeding's alterations in their own patients and to take in consideration that these alterations may not be transitory.

Correct advice and support at this critical time could be a determining factor of breastfeeding's continuation, and further studies should focus on interventions to prevent unwanted weaning.

Acknowledgements The authors thank Mrs Guillemette Roy, UGET Translations, Paris, France, for her English editing.

Contributors $\mathrm{CH}$ conceptualised and designed the study, drafted the initial manuscript, analysed the data, reviewed and revised the manuscript, and approved the final manuscript as submitted. ER, AH, AM and SR participated in patient's selection and data collection, reviewed and revised the manuscript, and approved the final manuscript as submitted. SS and SJ managed patient's selection and interrogation, critically reviewed the manuscript and approved the final manuscript as submitted. VR helped conceptualise and design the study, coordinated and supervised data collection, reviewed and revised the manuscript, and approved the final manuscript as submitted.

Competing interests SJ and SS both received a grant from the Regional Agency for Health (ARS IDF) but have no other conflict of interest to disclose. The other authors have indicated that they have no financial relationships relevant to this article to disclose.

Ethics approval CER SFP.

Provenance and peer review Not commissioned; externally peer reviewed.

Data sharing statement № additional unpublished data from the study.

Open Access This is an Open Access article distributed in accordance with the Creative Commons Attribution Non Commercial (CC BY-NC 4.0) license, which permits others to distribute, remix, adapt, build upon this work non-commercially, and license their derivative works on different terms, provided the original work is properly cited and the use is non-commercial. See: http://creativecommons.org/ licenses/by-nc/4.0/

(c) Article author(s) (or their employer(s) unless otherwise stated in the text of the article) 2017. All rights reserved. No commercial use is permitted unless otherwise expressly granted.

\section{REFERENCES}

1. Kramer MS, Kakuma R. The Cochrane CollaborationOptimal duration of exclusive breastfeeding. In: ed. Cochrane Database of Systematic Reviews. Chichester, UK: John Wiley \& Sons, Ltd, 2002. http://doi.wiley.com/10.1002/14651858.CD003517 (accessed 27 Sep 2016).

2. World Health Organization. Infant and young child feeding: model chapter for textbooks for medical students and allied health professionals, 2009. http://www.ncbi.nlm.nih.gov/books/ NBK148965/ (accessed 27 Sep 2016).

3. Cattaneo A, Yngve A, Koletzko B, et al. Protection, promotion and support of breast-feeding in Europe: current situation. Public Health Nutr 2005;8:39-46.

4. Salanave B, de Launay C, Bouder-Berquier J, et al. Durée de l'allaitement maternel en France (Épifane 2012-2013). Bull Epidémiol Hebd 2014;2014:450-7.

5. Kersuzan C, Gojard S, Tichit C, et al. Prévalence de l'allaitement à la maternité selon les caractéristiques des parents et les conditions de l'accouchement. Résultats de l'enquête elfe maternité, France métropolitaine, 2011. Bull Epidémiol Hebd 2014;2014:440-9.

6. Consensus conference on the management of infant bronchiolitis. Paris, France, 21September 2000.Proceedings]. Arch PédiatrieOrgane Off Sociéte Fr Pédiatrie 2000;2001(Suppl 1):1s-196.

7. Che $D$, Caillère N, Josseran L. Surveillance and epidemiology of infant bronchiolitis in France. Arch PédiatrieOrgane Off Sociéte Fr Pédiatrie 2008;15:327-8.

8. Fortin N, Gras-Le Guen C, Picherot G, et al. aractéristiques des épidémies de bronchiolite dans l'agglomération nantaise, 2007 to 2012: apport de différentes sources de données. Bull Epidémiol Hebd 2014;2014:58-64.

9. Lapillonne A, Regnault A, Gournay V, et al. Development of a questionnaire to assess the impact on parents of their infant's bronchiolitis hospitalization. BMC Health Serv Res 2013;13:272.

10. Lapillonne A, Regnault A, Gournay V, et al. Impact on parents of bronchiolitis hospitalization of full-term, preterm and congenital heart disease infants. BMC Pediatr 2012;12:171.

11. Ralston SL, Lieberthal AS, Meissner HC, et al. Clinical practice guideline: the diagnosis, management, and prevention of bronchiolitis. Pediatrics 2014;134:e1474-e1502.

12. Turck $D$, Vidailhet $M$, Bocquet $A$, et al. Allaitement maternel : les bénéfices pour la santé de l'enfant et de sa mère. Archives de Pédiatrie 2013;20:S29-S48.

13. Ajetunmobi OM, Whyte $\mathrm{B}$, Chalmers J, et al. Breastfeeding is associated with reduced childhood hospitalization: evidence from a Scottish Birth Cohort (1997 to 2009). J Pediatr 2015;166:620-5. 